\title{
SIMULASI PERANCANGAN DENAH VIRTUAL REALITY DAN DIGITAL SIGNAGE DI MALL
}

\author{
Zigrozora Krishy Aldodhery ${ }^{1}$, Mungki Astiningrum ${ }^{2}$ Rawansyah $^{3}$ \\ ${ }^{123}$ Program Studi Teknik Informatika, Jurusan Teknik Elektro, Politeknik Negeri Malang \\ ${ }^{1}$ zigrozora@gmail.com, ${ }^{2}$ mama.zahra@gmail.com, ${ }^{3}$ rawansyah@yahoo.com
}

\begin{abstract}
Abstrak
Malang Town Square (Matos) merupakan salah satu mall di Malang yang mempunyai bangunan besar, luas, dan mempunyai banyak toko di setiap lantai. Dengan banyaknya toko yang terdapat di Matos, pengunjung akan kesulitan untuk mencari toko yang akan dituju. Salah satu cara mengatasinya adalah dengan membuat virtual reality pada Matos dimana pengunjung seakan-akan menjelajahi Matos dengan tampilan 3-Dimensi (3D) dan dapat melakukan pencarian toko yang ingin dituju.

Media promosi adalah salah satu komponen penting untuk mempromosikan suatu produk kepada konsumen. Agar membuat media promosi menjadi lebih menarik bagi konsumen, salah satu caranya adalah dengan menampilkan dengan teknologi baru yaitu digital signage. Konten pada digital signage akan diklasifikasi dan diarahkan sesuai dengan demographic audience dan dibagi menjadi 2 kategori yaitu menurut umur dan jenis kelamin pengunjung. Fitur digital signage ditampilkan dengan cara screen saver yaitu jika website tidak sedang digunakan (idle) maka digital signage akan muncul dan jika website digunakan akan menutup.

3D modelling dibuat menggunakan Google SketchUp dan Unity 3D sebagai game engine untuk membuat lingkungan virtual yang kemudian di-build ke web agar dapat dijalankan pada website dengan plugin Unity Web Player. Kemudian virtual reality akan digabung dengan hasil pembuatan website dan digital signage yang dapat di-manage oleh admin yang berguna untuk menampilkan dan mengolah data. Aplikasi ini sudah diujicobakan pada beberapa pengguna dengan mengunggah ke web hosting. Berdasarkan hasil ujicoba tersebut dapat disimpulkan bahwa website ini dinilai dengan sangat baik, desain aplikasi menarik, serta informasi yang disajikan menarik dan informatif.
\end{abstract}

Kata Kunci : simulasi, Virtual Reality, Digital Signage, mall

\section{Pendahuluan}

Pusat perbelanjaan adalah sekelompok penjual eceran dan usahawan komersi lainnya yang merencanakan, mengembangkan, mendirikan, memiliki dan mengelola sebuah properti tunggal (Septiadi, 2009). Malang Town Square (Matos) yang terletak di kota Malang merupakan salah satu pusat perbelanjaan yang dikunjungi masyarakat Malang maupun luar kota. Matos terdiri dari 3 lantai dan terdapat banyak gerai di dalamnya. Banyaknya gerai yang terletak di 3 lantai tersebut membuat pengunjung yang malas atau dikejar waktu untuk membeli suatu kebutuhan akan sangat kesusahan untuk mencari gerai yang dituju.

Saat ini belum ada layanan atau suatu aplikasi yang berbentuk virtual reality untuk denah pada Malang Town Square. Virtual reality adalah lingkungan tiruan yang diciptakan dengan perangkat keras dan perangkat lunak computer dan disajikan kepada pemakai sehingga pemakai tersebut merasakan seperti dalam lingkungan nyata (Suyanto, 2005).

Website simulasi perancangan denah virtual reality dan digital signage di mall akan dibuat agar bisa menarik pengunjung untuk bisa menjelajahi Matos. Website ini memberikan informasi apa saja tentang gerai yang dituju. Tampilan pemetaan denah Matos berbentuk 3D, jadi seakan-akan pengunjung yang mengoperasikannya selayaknya bermain game untuk menjelajahi gerai yang ada di Matos. Dengan tampilan 3D diharapkan bisa membuat pengunjung lebih tertarik dan menarik lebih banyak pengunjung lagi ke Matos.

Banyak produk-produk di dunia ini yang bersaing dan memasang iklannya di mall. Salah satu pemasangan iklan di mall yang sudah canggih saat ini adalah digital signage. Digital signage adalah media iklan dimana isi dan pesan ditampilkan pada layar elektronik dan iklan dapat diubah dengan otomatis dan dengan waktu yang dapat diatur (Schaeffler, 2008).

Fitur digital signage muncul pada saat aplikasi tidak dipakai (idle) sehingga bisa menjadi media promosi bagi produk-produk di Matos. Selain itu terdapat pengklasifikasian iklan dengan demographic audience agar konten dari toko-toko dan iklan yang ditampilkan sesuai dengan umur dan jenis kelamin pengunjung/pengguna yang sedang mengakses website. Untuk memanajemen iklan yang hanya membayar atau terikat kontrak terbatas, maka dibuat juga sistem administrasi untuk memanajemen iklan yang sudah habis masa kontraknya. Agar iklan bisa menyebar luas, maka aplikasi ini dapat diakses dimana saja melalui website sehingga bisa juga menjadi salah satu strategi untuk promosi pada digital signage di Matos.

Hasil yang diharapkan adalah sebuah website interaktif untuk pengunjung yang dapat menampilkan informasi tentang Malang Town Square yang ditampilkan secara informatif dan visual. Digital 
signage akan tampil seperti screen saver pada komputer jika komputer tidak sedang digunakan (idle).

\section{Metode}

\subsection{Metodologi Penelitian}

Penelitian akan dilakukan dengan mengikuti tahapan-tahapan waterfall sebagai berikut :

a. Pengumpulan Data

i) Data Primer

Pengumpulan data primer dilakukan secara langsung melalui pengamatan di lapangan dan wawancara langsung (jika diperlukan) untuk menemukan atau mengindentifikasi masalah yang ada. Pembuatan kuesioner kebutuhan aplikasi yang disebar kepada pihak manajemen Matos sebagai analisa untuk mengetahui apakah aplikasi dibutuhkan atau tidak.

ii) Data sekunder

Pengumpulan data sekunder dilakukan dengan cara mencari atau menentukan landasan teori yang berkesusuaian bagi penyusunan skripsi ini. Penulis membaca, memahami, mengutip, dan membuat kesimpulan dari buku-buku, jurnal maupun skripsi yang berkaitan dengan penelitian ini. Pencarian dari beberapa situs internet untuk mengumpulkan informasi yang berhubungan dengan hal-hal yang dibahas.

b. Analisis

Analisis dilakukan dengan menganalisa hasil kuesioner kebutuhan aplikasi untuk Matos, menganalisa bagaimana cara menampilkan konten toko dan iklan sesuai dengan umur dan jenis kelamin pengunjung/pengguna website dengan cara demographic audience, dan menganalisa hasil kuesioner penilaian website.

c. Perancangan Sistem

i) Perancangan $3 \mathrm{D}$ modelling

Perancangan 3D modelling merupakan tahapan-tahapan modelling objek 3D yang terdiri dari beberapa tahap yaitu perancangan denah Malang Town Square dan perancangan asset yang ditampilkan pada gambar 2.1 yaitu arsitektur sistem pada 3D Modelling.

ii) Perancangan Desain Sistem Website

Perancangan desain sistem website meliputi use case diagram admin yang ditampilkan pada gambar 2.2, use case diagram pengguna yang ditampilkan pada gambar 2.3 dan Data Flow Diagram (DFD).

iii) Perancangan Database

Perancangan database merupakan rincian isi tabel yang ada pada database website Matos yang dibuat dengan membuat Conceptual Data Model (CDM) dan Physical Data Model (PDM).

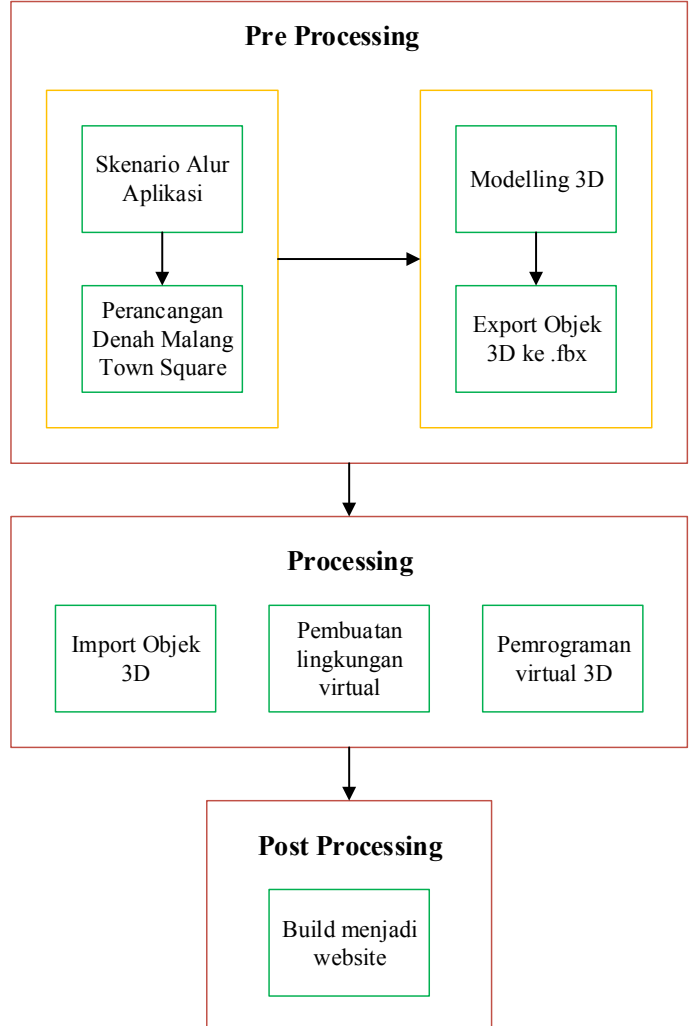

Gambar 2.1 Arsitektur Sistem Pada 3D Modeling

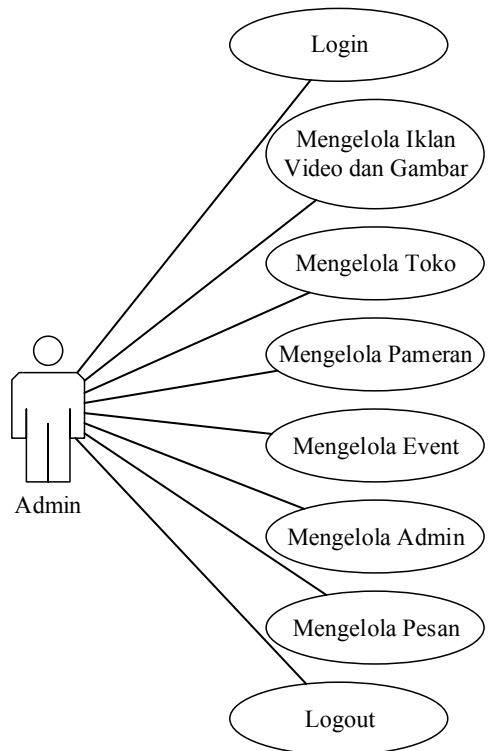

Gambar 2.2 Use Case Diagram Admin

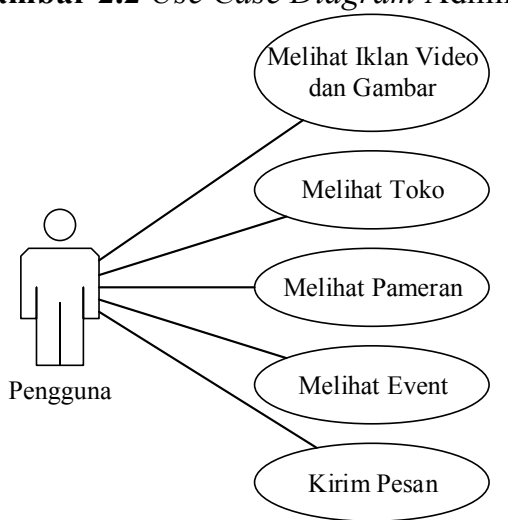

Gambar 2.3 Use Case Diagram Pengguna 


\section{d. Implementasi Sistem}

Dari perancangan sistem yang telah didapat, tahap berikutnya diimplementasikan dengan membuat obyek 3D yang dibuat dengan Google SkecthUp 2014 lalu diekspor ke dalam file yang berekstensi filmbox (.fbx) agar dapat diimpor ke dalam aplikasi Unity 3D dalam pembuatan lingkungan virtual. Hasil pembuatan virtual di dalam aplikasi Unity 3D di-build ke web agar bisa dijalankan di dalam browser. Untuk membuka file di Unity 3D yang sudah di-build ke website harus meng-install plugin Unity Web Player.

Pada pembuatan halaman pengunjung dan admin pada website, dibuat menggunakan bahasa pemrograman PHP dan database MySQL. Proses pembuatan manajemen digital signage atau iklan menggunakan javascript agar bisa muncul seperti screen saver.

e. Pengujian Sistem

Pengujian sistem dilakukan dengan menggunakan metode BlackBox Testing. BlackBox Testing memberikan hasil tes kesesuaian aplikasi dengan fungsi atau kemampuan sistem secara fungsional.

BlackBox Testing berusaha menemukan kesalahan yang termasuk kategori dibawah ini :

i) Fungsi-fungsi yang hilang atau tidak benar.

ii) Kesalahan pada design interface.

iii) Kesalahan pada performance.

iv) Kesalahan pada inisialisasi dan terminasi.

Jika sudah tidak ditemukan kesalahan pada seluruh fungsi, website akan di-upload ke dalam web hosting agar bisa diakses secara online.

Untuk melakukan analisa dilakukan pengujian di beberapa browser apakah hasil yang diharapkan sesuai dan menghasilkan tampilan yang konsisten. Setelah itu akan dilakukan pengujian terhadap pengunjung/user dan memberikan kuesioner penilaian website.

\subsection{Alat dan Bahan Penelitian}

Alat dan bahan penelitian yang digunakan adalah sebagai berikut :

a. Komputer/laptop.

b. Windows 8.1.

c. Google SketcUp 2014 untuk membuat desain 3D denah Malang Town Square.

d. Unity 3D untuk membuat virtual reality pada Malang Town Square.

e. Apache Webserver dan XAMPP sebagai web server.

f. MySQL sebagai DBMS untuk database.

g. Bahasa pemrograman PHP.

h. Sublime 3 sebagai text editor.

i. Web hosting untuk dapat mengakses website secara online.

\section{Hasil}

Website yang dihasilkan mempunyai 2 halaman utama yang tidak berhubungan yaitu halaman pengunjung dan halaman administrator. Halaman tidak dihubungkan karena pengunjung tidak berhak untuk mengakses, mendaftar, dan masuk ke dalam halaman administrator. Pengunjung hanya bisa mengakses halaman utama yang berisi informasiinformasi yang berkaitan dengan Malang Town Square. Pengunjung dapat melihat informasi yang ada dan memberikan komentar atau pesan kepada admin melalui website.

Sedangkan halaman admin hanya bisa diakses oleh admin yang sudah terdaftar yaitu pihak manajemen Malang Town Square. Admin mempunyai hak akses untuk menambah, mengubah, dan menghapus data. Admin mempunyai autorisasi untuk mengubah dan menghapus data tertentu untuk mengurangi human error atau kejadian yang tidak diinginkan. Admin juga dapat mencetak detail iklan dan grafik untuk dijadikan sebagai laporan.

Berikut ini adalah beberapa tampilan aplikasi yang telah dibuat :

a. Halaman Utama Pengunjung

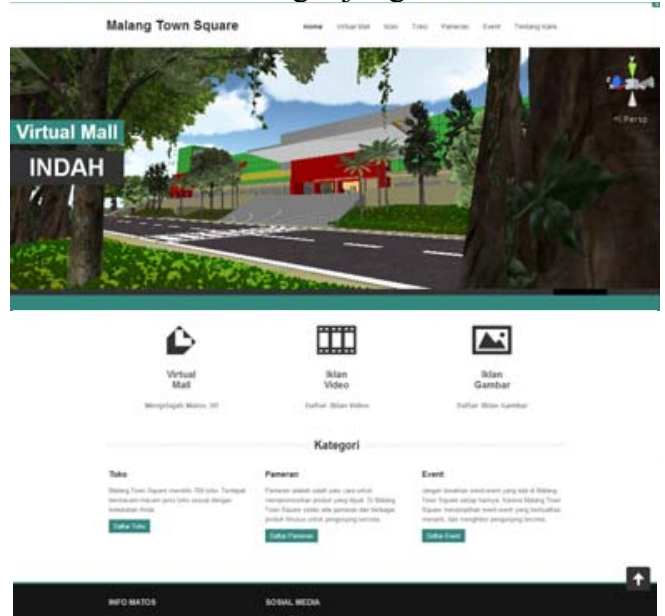

Gambar 3.1 Tampilan Halaman Utama Pengunjung

Halaman utama pengunjung ini dapat diakses oleh pengunjung yang menampilkan slide gambar Malang Town Square dan pilihan menu-menu utama website.

b. Halaman Virtual Reality

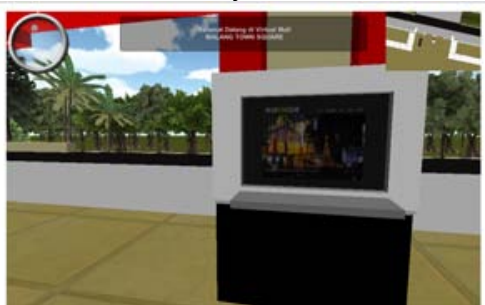

Gambar 3.2 Tampilan Saat Virtual Reality Dijalankan

Tampilan halaman virtual reality diatas adalah saat pengunjung menjalankan virtual reality pada Malang Town Square.

c. Halaman Saat Iklan Muncul (Idle) 


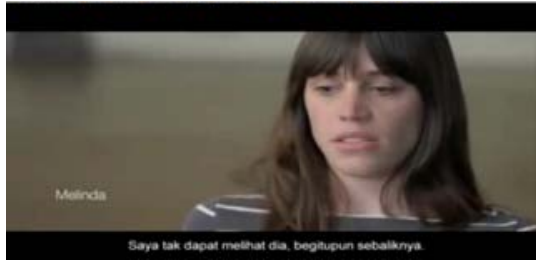

Gambar 3.3 Tampilan Saat Iklan Muncul (Idle)

Halaman saat iklan atau digital signage muncul (idle) akan ditampilkan secara penuh pada halaman tersebut. Iklan muncul jika website tidak sedang digunakan (idle). Jika halaman digunakan kembali maka tampilan iklan akan tertutup.

d. Halaman Kontak Kami

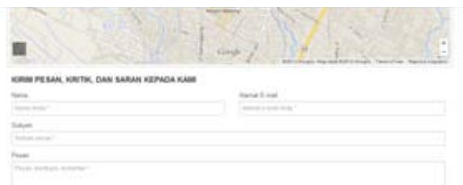

므

Gambar 3.4 Tampilan Halaman Kontak

Halaman kontak kami dapat mengirimkan pesan kepada admin yang dilakukan oleh pengunjung, sehingga pengunjung dapat berhubungan langsung dengan admin. Selain halaman kontak kami, terdapat di setiap toko, pameran, dan event yang memiliki fitur mengirim pesan. Saat mengirim pesan, otomatis akan mengirim email ke email pengisi.

e. Halaman Login Admin

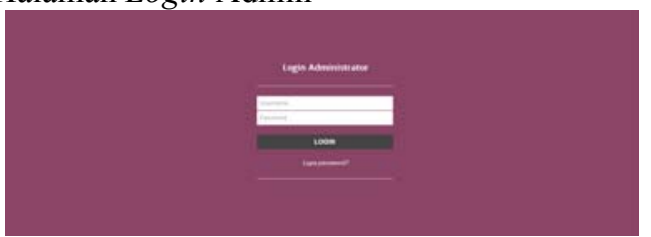

Gambar 3.5 Tampilan Halaman Login Admin

Halaman login admin digunakan untuk masuk ke halaman utama administrator.

f. Halaman Utama Admin

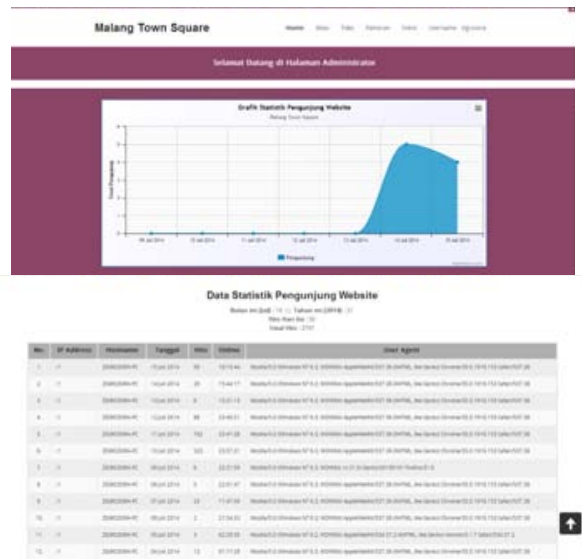

Gambar 3.6 Halaman Utama Admin

Halaman utama admin menampilkan statistik data pengunjung yang ditampilkan secara grafik dan tabel. Statistik data pengunjung dapat langsung dicetak, diunduh menjadi gambar atau pdf.

\section{Pembahasan}

\subsection{Analisa Kebutuhan Website}

Kuesioner kebutuhan website terdiri dari 9 pertanyaan dan disebar ke 10 responden yaitu manajemen Malang Town Square. Setiap pertanyaan pada kuesioner mempunyai format jawaban 2 pilihan yaitu 'Ya' atau 'Tidak' disertai dengan alasan responden (tidak wajib diisi).

Berikut ini adalah daftar 10 pertanyaan pada kuesioner kebutuhan website:

i) Apakah dibutuhkan media informasi yang informatif dan menarik agar pengunjung Malang Town Square lebih tertarik menggunakannya?

ii) Apakah dibutuhkan website yang memiliki fitur denah dan bentuk 3-Dimensi (3D) pada Malang Town Square?

iii) Apakah dengan adanya fitur denah dan bentuk 3-Dimensi pada Malang Town Square akan menarik pengguna atau pengunjung untuk menggunaknnya?

iv) Apakah dengan adanya fitur denah dan bentuk 3-Dimensi pada Malang Town Square akan mempermudah pengguna atau pengunjung untuk menjelajahi Malang Town Square?

v) Apakah dibutuhkan suatu teknologi baru yang dapat menampilkan iklan dengan model yang lebih menarik?

vi) Jika dibutuhkan, apakah dengan teknologi tersebut akan membuat lebih banyak iklan yang ingin mempromosikan di Malang Town Square?

vii) Apakah dengan mengembangkan teknologi tersebut dengan cara menampilkan di internet akan lebih menarik?

viii) Apakah dengan adanya teknologi baru untuk menampilkan iklan tersebut akan membantu dan memperluas proses promosi iklan yang ada di Malang Town Square?

ix) Apakah dengan menampilkan iklan tersebut dengan teknologi yang baru akan menarik pengguna dan pengunjung untuk membaca atau melihat iklan yang tampil? berikut :

Hasil dari kuesioner kebutuhan website sebagai

Tabel 4.1 Hasil Kuesioner Kebutuhan Website

\begin{tabular}{|c|c|c|c|c|c|c|c|c|c|c|}
\hline & \multicolumn{9}{|c|}{ Pertanyaan } \\
\hline & & 1 & 2 & 3 & 4 & 5 & 6 & 7 & 8 & 9 \\
\hline \multirow{10}{*}{$\begin{array}{l}\text { లే } \\
\text { D̃ } \\
\text { के } \\
\text { ป }\end{array}$} & 1 & $\mathrm{a}$ & $\mathrm{a}$ & $\mathrm{a}$ & $\mathrm{a}$ & $\mathrm{a}$ & $\mathrm{a}$ & $\mathrm{a}$ & $\mathrm{a}$ & $\mathrm{a}$ \\
\hline & 2 & $\mathrm{a}$ & $\mathrm{a}$ & $\mathrm{a}$ & $x$ & $\mathrm{a}$ & $x$ & $\mathrm{a}$ & $\mathrm{a}$ & $x$ \\
\hline & 3 & $\mathrm{a}$ & $\mathrm{a}$ & $\mathrm{a}$ & $\mathrm{a}$ & $\mathrm{a}$ & $\mathrm{a}$ & $\mathrm{a}$ & $\mathrm{a}$ & $\mathrm{a}$ \\
\hline & 4 & $\mathrm{a}$ & $\mathrm{a}$ & $\mathrm{a}$ & $\mathrm{a}$ & $\mathrm{a}$ & $\mathrm{a}$ & $\mathrm{a}$ & $\mathrm{a}$ & $\mathrm{a}$ \\
\hline & 5 & $\mathrm{a}$ & $\mathrm{a}$ & $\mathrm{a}$ & $\mathrm{a}$ & $\mathrm{a}$ & $\mathrm{a}$ & $\mathrm{a}$ & $\mathrm{a}$ & $\mathrm{a}$ \\
\hline & 6 & $\mathrm{a}$ & $\mathrm{a}$ & $\mathrm{a}$ & $\mathrm{a}$ & $\mathrm{a}$ & $\mathrm{a}$ & $\mathrm{a}$ & $\mathrm{a}$ & $\mathrm{a}$ \\
\hline & 7 & $\mathrm{a}$ & $\mathrm{a}$ & $\mathrm{a}$ & $\mathrm{a}$ & $\mathrm{a}$ & $\mathrm{a}$ & $\mathrm{a}$ & $\mathrm{a}$ & $\mathrm{a}$ \\
\hline & 8 & $\mathrm{a}$ & $\mathrm{a}$ & $\mathrm{a}$ & $\mathrm{a}$ & $\mathrm{a}$ & $\mathrm{a}$ & $\mathrm{a}$ & $\mathrm{a}$ & $\mathrm{a}$ \\
\hline & 9 & $\mathrm{a}$ & $\mathrm{a}$ & $\mathrm{a}$ & $x$ & $\mathrm{a}$ & $\mathrm{a}$ & $\mathrm{a}$ & $\mathrm{a}$ & $x$ \\
\hline & 10 & $\mathrm{a}$ & $\mathrm{a}$ & $\mathrm{a}$ & $x$ & $\mathrm{a}$ & $x$ & $\mathrm{a}$ & $\mathrm{a}$ & $\mathrm{a}$ \\
\hline \multicolumn{2}{|c|}{ Totala } & 10 & 10 & 10 & 7 & 10 & 8 & 10 & 10 & 8 \\
\hline \multicolumn{2}{|c|}{ Total $\times$} & 0 & 0 & 0 & 3 & 0 & 2 & 0 & 0 & 2 \\
\hline
\end{tabular}


Keterangan :

$\mathrm{a}=$ Responden menjawab 'Ya'

$x=$ Responden menjawab 'Tidak'

Dari tabel 4.1 dapat disimpulkan dari hasil kuesioner kebutuhan website bahwa dibutuhkan website Matos yang lebih menarik, interaktif, dan informatif yaitu dengan membuat pemetaan denah Matos secara 3D dan media promosi dengan teknologi baru.

Media promosi dengan teknologi baru salah satunya adalah digital signage. Untuk menambah menarik lagi dan interaktif maka digital signage dibuat sedemikian rupa seperti screen saver pada website.

\subsection{Analisa Pengujian Fungsional}

Pada pengujian fungsional dilakukan dengan cara upload ke web hosting sehingga bisa diakses secara online. Setelah itu website diujikan di beberapa browser pada sistem operasi Windows 8.1. Browser sudah harus ter-install plugin unity web player untuk dapat mengakses virtual reality dan plugin flash player yang terbaru untuk menampilkan iklan video. Browser yang digunakan adalah Google Chrome, Mozilla Firefox, Internet Explorer, Opera, Comodo Dragon, dan Safari. Performa virtual reality dan digital signage juga tergantung dengan spesifikasi hardware komputer/laptop dan kecepatan koneksi internet pengguna.

Setelah di uji coba di beberapa browser pada sistem operasi Windows 8.1, browser Google, Chrome, Mozilla Firefox, Internet Explorer, Opera, dan Comodo Dragon memiliki kualitas tampilan yang sama, konsisten, dan semua fungsi berjalan semua tanpa ada error.

Sedangkan pada browser Safari di sistem operasi Windows 8.1 pada saat screen saver berupa digital signage muncul dan pada saat website digunakan, screen saver tidak menutup. Selain itu suara menu navigasi pada website juga tidak bisa keluar. Itu dikarenakan browser Safari lebih optimal digunakan pada sistem operasi iOS. Pengujian browser Safari dilakukan juga pada sistem operasi Mac OS X yang dilakukan oleh pengguna dan hasilnya memiliki kualitas tampilan yang baik dan semua fungsi berjalan lancar tanpa ada error.

\subsection{Analisa Pengujian Kegunaan}

Pengujian kegunaan dilakukan dengan membuat kuesioner penilaian penggunaan aplikasi untuk mengukur tingkat kemudahan operasional aplikasi, kepuasan pengguna, dan penilaian desain interface aplikasi.

Kuesioner dibagi menjadi beberapa kriteria penilaian dengan 5 opsi jawaban dan cara

menjawabnya adalah memilih salah satu dari lima penilaian yaitu sangat baik (SB) dengan nilai 5, baik (B) dengan nilai 4, cukup baik (CB) dengan nilai 3, kurang baik $(\mathrm{KB})$ dengan nilai 2, dan sangat kurang baik (SKB) dengan nilai 1 .

Pengujian dilakukan kepada 20 orang. Terdiri dari 19 orang mengakses menggunakan sistem operasi Windows dengan browser Google Chrome dan 1 orang mengakses menggunakan sistem operasi Mac OS X dengan browser Safari. Berikut merupakan hasil kuesioner penilaian website seperti pada tabel 4.2 .

Tabel 4.2 Hasil Kuesioner Penilaian Website

\begin{tabular}{|c|c|c|}
\hline No. & Kriteria Penilaian & Hasil \\
\hline \multirow{5}{*}{1.} & \multicolumn{2}{|l|}{ Kecepatan Akses Website } \\
\hline & $\begin{array}{l}\text { 1.1 Membuka tampilan awal } \\
\text { (Home) }\end{array}$ & Baik (75\%) \\
\hline & 1.2 Membuka konten/isi & Baik $(70 \%)$ \\
\hline & $\begin{array}{l}\text { 1.3 Kecepatan pencarian informasi } \\
\text { (search) }\end{array}$ & Baik (55\%) \\
\hline & $\begin{array}{l}\text { 1.4 Kecepatan dalam memberikan } \\
\text { respon ketika memproses } \\
\text { sesuatu }\end{array}$ & Baik (50\%) \\
\hline \multirow{10}{*}{2.} & \multicolumn{2}{|l|}{ Kualitas Interaksi (Usability) } \\
\hline & $\begin{array}{l}\text { 2.1 Kemudahan } \\
\text { interaksi/pengoperasian dengan } \\
\text { website (user friendly) }\end{array}$ & Baik $(70 \%)$ \\
\hline & $\begin{array}{c}2.2 \text { Website memberikan umpan } \\
\text { balik (feedback) yang jelas } \\
\text { ketika memproses sesuatu }\end{array}$ & Baik $(60 \%)$ \\
\hline & $\begin{array}{l}2.3 \text { Kemudahan memberikan } \\
\text { komentar pada admin }\end{array}$ & Baik $(60 \%)$ \\
\hline & 2.4 Desain interface & $\begin{array}{l}\text { Sangat baik } \\
(30 \%), \\
\text { Baik (30\%) } \\
\text { Cukup Baik } \\
(30 \%)\end{array}$ \\
\hline & $\begin{array}{l}\text { 2.5 Tampilan website konsisten dan } \\
\text { memiliki nuansa yang sama }\end{array}$ & Baik $(65 \%)$ \\
\hline & 2.6 Tata letak konten (layout) & Baik $(50 \%)$ \\
\hline & 2.7 Struktur menu dan navigasi & Baik $(65 \%)$ \\
\hline & 2.8 Warna teks & Baik $(70 \%)$ \\
\hline & $\begin{array}{l}\text { 2.9 Jenis huruf yang digunakan pada } \\
\text { halaman website mudah dibaca }\end{array}$ & Baik $(90 \%)$ \\
\hline \multirow{4}{*}{3.} & \multicolumn{2}{|l|}{ Konten/Isi } \\
\hline & $\begin{array}{l}\text { 3.1 Bahasa yang digunakan mudah } \\
\text { untuk dipahami }\end{array}$ & Baik (40\%) \\
\hline & $\begin{array}{l}\text { 3.2 Kemudahan dalam pencarian } \\
\text { informasi }\end{array}$ & Baik $(60 \%)$ \\
\hline & $\begin{array}{l}\text { 3.3 Dapat mencari informasi yang } \\
\text { dibutuhkan pengunjung dengan } \\
\text { cepat dan mudah }\end{array}$ & $\begin{array}{l}\text { Cukup Baik } \\
(50 \%)\end{array}$ \\
\hline
\end{tabular}




\begin{tabular}{|c|c|c|}
\hline & $\begin{array}{l}\text { 3.4 Informasi yang ditampilkan jelas } \\
\text { dan lengkap }\end{array}$ & Baik (45\%) \\
\hline & $\begin{array}{l}\text { 3.5 Informasi yang ditampilkan } \\
\text { bermanfaat bagi pengunjung }\end{array}$ & Baik (55\%) \\
\hline & $\begin{array}{l}\text { 3.6 Kualitas informasi yang } \\
\text { ditampilkan }\end{array}$ & Baik $(65 \%)$ \\
\hline & $\begin{array}{l}\text { 3.7 Informasi yang ditampilkan } \\
\text { menarik pengunjung }\end{array}$ & Baik $(80 \%)$ \\
\hline \multirow{8}{*}{4.} & \multicolumn{2}{|l|}{ Virtual Reality } \\
\hline & 4.1 Kecepatan menampilkan 3D & Baik $(40 \%)$ \\
\hline & $\begin{array}{l}4.2 \text { Petunjuk penggunaan virtual } \\
\text { reality }\end{array}$ & Baik $(55 \%)$ \\
\hline & $\begin{array}{l}\text { 4.3 Desain 3D model pada Malang } \\
\text { Town Square }\end{array}$ & Baik $(40 \%)$ \\
\hline & $\begin{array}{l}\text { 4.4 Kemiripan 3D model dengan } \\
\text { Malang Town Square yang asli }\end{array}$ & $\begin{array}{l}\text { Cukup Baik } \\
(45 \%)\end{array}$ \\
\hline & $\begin{array}{l}\text { 4.5 Kemudahan dalam menjelajahi } \\
\text { 3D }\end{array}$ & Baik $(60 \%)$ \\
\hline & $\begin{array}{l}\text { 4.6 Tata letak informasi pada } \\
\text { gerai/toko }\end{array}$ & Baik (50\%) \\
\hline & $\begin{array}{l}\text { 4.7 Kemudahan dibaca, dimengerti, } \\
\text { dan dipahami (informasi) pada } \\
\text { gerai/toko }\end{array}$ & Baik $(65 \%)$ \\
\hline \multirow{4}{*}{5.} & \multicolumn{2}{|l|}{ Digital Signage (Iklan) } \\
\hline & $\begin{array}{l}\text { 5.1 Kecepatan menampilkan iklan } \\
\text { (screen saver) }\end{array}$ & Baik $(50 \%)$ \\
\hline & $\begin{array}{l}\text { 5.2 Kecepatan pergantian dari iklan } \\
\text { satu ke iklan lainnya }\end{array}$ & Baik $(50 \%)$ \\
\hline & 5.3 Tata letak digital signage & Baik $(65 \%)$ \\
\hline \multirow{3}{*}{6.} & \multicolumn{2}{|l|}{ Penggunaan Platform } \\
\hline & 6.1 Dukungan browser & Baik $(60 \%)$ \\
\hline & 6.2 Dukungan sistem operasi & Baik $(65 \%)$ \\
\hline
\end{tabular}

Keterangan : Hasil yang dicantumkan merupakan prosentase terbanyak dari responden di setiap kriteria penilaian

Dapat disimpulkan bahwa penilaian responden/user terhadap website Malang Town Square secara umum adalah baik.

\section{Penutup}

\subsection{Kesimpulan}

Berdasarkan hasil penelitian yang telah dilakukan, maka dapat ditarik kesimpulan sebagai berikut :

a. Website simulasi perancangan denah vitrual reality dan digital signage di mall yang dibuat memberikan hiburan dan kemudahan bagi pengguna atau pengunjung karena dengan adanya fitur virtual reality membuat pengguna dapat seolah-olah menjelajahi dan merasakan suasana lingkungan yang ada pada Malang Town Square.

b. Aplikasi simulasi perancangan denah vitual reality dan digital signage di mall yang dibuat menampilkan teknologi baru di bidang periklanan yaitu screen saver yang di dalamanya terdapat konten digital signage (iklan) berbasis website.

c. Hasil respon dari pengguna terhadap website Malang Town Square menunjukkan bahwa sudah dapat memvisualisasikan lingkungan pada Malang Town Square, desain aplikasi menarik, serta informasi yang disajikan cukup menarik dan informatif.

\subsection{Saran}

Saran yang didapat untuk mengembangkan aplikasi ini menjadi lebih baik lagi antara lain adalah:

a. Pengembangan website virtual reality dan digital signage ke platform yang lain, seperti iOS, Android, dan Windows Phone.

b. Pembuatan augmented virtuality untuk 3D modelling-nya sebagai media promosi agar menjadi lebih menarik.

\section{Daftar Rujukan}

Afida, Rila Mawwala, Achmad Basuki, Rizky Yuniar Hakkun. (2014): 3D Virtual Tour Situs Sejarah Candi Jago Kabupaten Malang Berbasis Android. Tugas Akhir. Teknik Informatika, Politeknik Elektronika Negeri Surabaya. Surabaya.

Schaeffler, Jimmy. (2008): Digital Signage: Software, Networks, Advertising, and Displays: A Primer for Understanding the Bussiness. Focal Press, Burlington.

Septiadi, Hendrian. (2009): Mal dan Apartemen di Jakarta Barat. Tugas Akhir. Teknik Arsitektur, Universitas Bina Nusantara. Jakarta.

Suyanto, M. (2005): Multimedia Alat Untuk Meningkatkan Keunggulan Bersaing. Penerbit Andi, Yogyakarta.

Suyanto, M. (2005): Pengantar Teknologi Informasi Untuk Bisnis. Penerbit Andi, Yogyakarta. 